\title{
Liquid nitrogen in the industrial practice of hot aluminum extrusion: experimental and numerical investigation
}

\author{
Riccardo Pelaccia ${ }^{1}$, Barbara Reggiani ${ }^{1}$, Marco Negozio $^{2}$, Lorenzo Donati $^{2}$ \\ ${ }^{1}$ DISMI Department of Sciences and Methods for Engineering, University of Modena and Reggio \\ Emilia, Via Amendola 2, 42122, Reggio Emilia, Italy. \\ ${ }^{2}$ DIN Department of Industrial Engineering, University of Bologna, Viale Risorgimento 2, 40136, \\ Bologna, Italy.
}

CORRESPONDING AUTHOR:

Riccardo Pelaccia

DISMI - Department of Sciences and Methods for Engineering, University of Modena and Reggio Emilia,

Viale Amendola 2, 42122, Reggio Emilia, Italy

tel:+39-0522-522652

e-mail: riccardo.pelaccia@unimore.it 


\begin{abstract}
Nowadays, the liquid nitrogen cooling in aluminium extrusion is a widely adopted industrial practice to increase the process productivity as well as to improve the extruded profile surface quality by reducing the profile exit temperatures. The cooling channels are commonly designed on the basis of die maker experience only, usually obtaining modest performances in terms of cooling efficiency. Trial-and-error approach is time and cost consuming, thus providing a relevant industrial interest in the development of reliable numerical simulations able to foresee and optimize the nitrogen cooling effect during the die design stage. In this work, an extensive experimental campaign was performed during the extrusion process of an AA6060 industrial hollow profile, in different conditions of nitrogen flow rate and ram speed. The monitored data (die and profile temperatures and extrusion load) were compared with the outputs of a fast and efficient numerical model proposed by the authors, and developed in the COMSOL Multiphysics code, able to compute not only the effect of nitrogen liquid flow but also the gaseous condition. The results of the simulations showed a good agreement with experimental data and evidenced how far was the experimental cooling channel design from an optimized condition.
\end{abstract}

Keywords: nitrogen cooling, extrusion, monitoring process, FEM, COMSOL 


\section{Introduction}

The hot aluminium extrusion is a well-consolidated industrial manufacturing process able to produce profiles of complex geometry, such as multi-hollow shapes and thin sections, by imposing high deformation rates [1-2]. The temperatures and the thermal gradients involved during the process affect its efficiency in terms of billet formability, profile quality as well as productivity and die lifetime [1-4]. Indeed, the control over the temperature is mandatory to optimize the extrusion process. If the billet pre-heating is required in order to suitably extrude the alloy, the deformation energy and the friction forces between the billet and the tools can lead to an excessive increase of temperatures both in the die and in the profile. This excessive exit profile temperature can cause several aesthetical defects or cracks on the profile surface, resulting in the scrap of the products or in the reduction of the service life of the tools [4-8]. The exit profile temperature strongly increases also with extrusion speed, thus generating relevant constraint in term of maximum achievable productivity [4].

Nowadays, the use of nitrogen cooling in aluminium extrusion dies is a well-known technology aimed at increasing the process speed, reducing die and tools temperature and improving the extruded profile surface quality [9-10]. Several papers on gas and liquid nitrogen applications aimed at increase dies performances were presented at the International Aluminium Extrusion Technology (ET) seminars [11-13]. Among the different tested solutions, liquid nitrogen was proved to be the most efficient one leading to double the extrusion speed $[9,13]$. In a different study, Donati et al. [14] monitored the thermal gradient during the extrusion of a hollow profile in uncooled and cooled conditions with liquid nitrogen, obtaining a decrease of temperature up to $80{ }^{\circ} \mathrm{C}$ nearby the bearing zones.

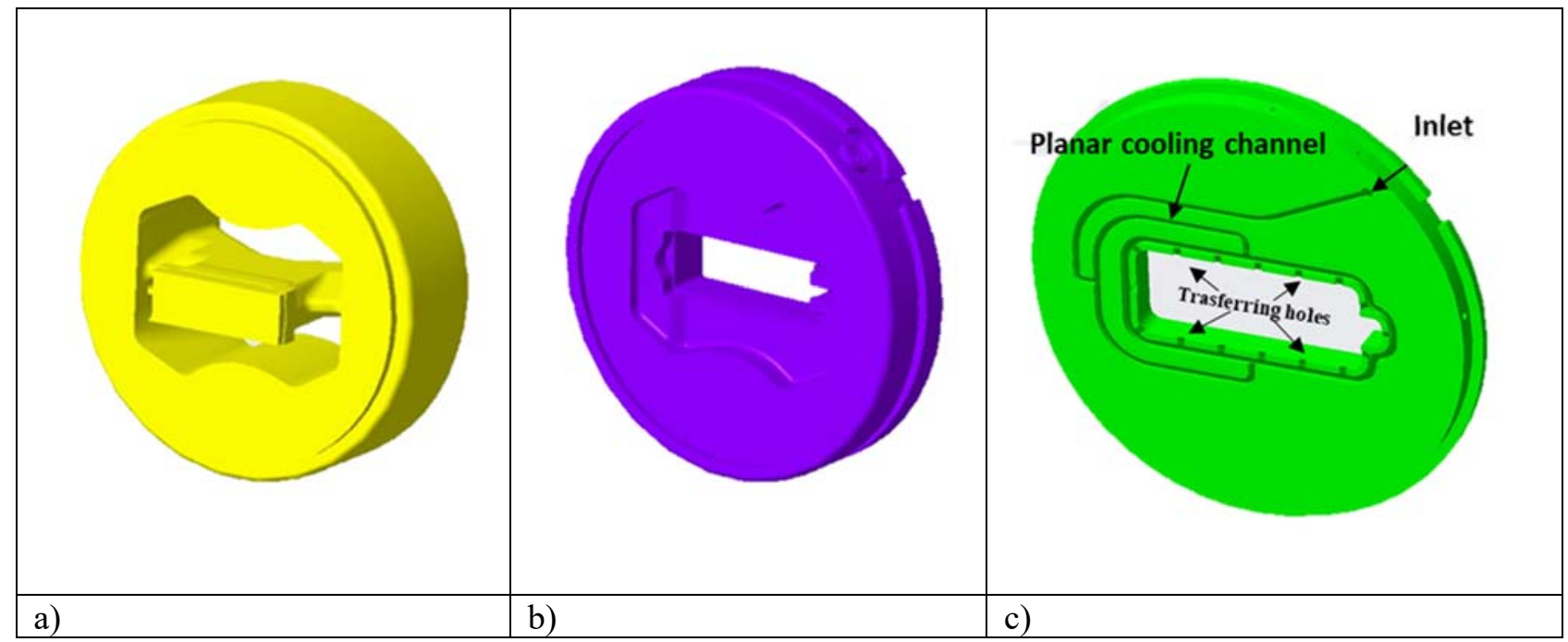

Fig.1 Porthole die: a) The mandrel; b) The die; c) The backer with the cooling channel

In the current industrial practice, the cooling channel is realized in the backer element of the die set and positioned close enough to the bearings zones, where the extruded profile gets its final shape and where, consequently, the highest temperatures are reached (Fig.1). Specifically, channels are milled on the backer face in contact with the die and a number of transferring holes shift the nitrogen to the profile surface (Fig. 1c). A greater cooling efficiency could be achieved by manufacturing the channels directly in the die, around the bearings; but this solution would require additive manufacturing technologies associated to greater costs, as discussed in the work of Reggiani and Todaro [15]. In both solutions, the cooling is localized nearby the profile exit, not involving the massive part of the deforming material and consequently minimally influencing the extrusion load. 
The nitrogen in the liquid phase subtracts heat from the tooling set and then, in a gaseous phase, chills the profile surface and prevents the profile oxidation [16-17]. However, nitrogen easily changes its state in gas when the temperature is higher than $-196^{\circ} \mathrm{C}$ at 1 bar [18]. This change means that different nitrogen phases may co-exists in the cooling channel. At the beginning of the extrusion process the whole cooling channel (Fig. 1c) is free from nitrogen, then, after the nitrogen valve opening, the channel is gradually filled by liquid nitrogen that immediately evolves in a gaseous state as a consequence of the hot backer. After some seconds, the channel nearby the inlet is gradually filled by liquid nitrogen while gaseous nitrogen is present in the remaining sections of the channel. Only after some minutes the cooling channel can be entirely filled by liquid nitrogen, while gaseous nitrogen can be found only after transferring holes. An optimized channel design promotes a transition to full liquid state within few extrusion runs, while a bad design may require several runs (up to a never achieving the complete transition). The differences in terms of cooling effectiveness between the liquid and the gas nitrogen is relevant since the liquid nitrogen heat capacity is about 1.8 times higher than the gaseous one. In addition, it has to be reminded that, during phase change from liquid to gas, nitrogen expands of 177 times in volume [18], leading to a significant pressure loss throughout the channel and consequently to a reduction of the nitrogen flow rate under constant inlet pressure. It comes clear that a bad channel design may promote an excessive formation of gaseous nitrogen that obstructs the channel, drastically reducing the flow rate and consequently the cooling efficiency.

Despite the significant interest in the use of liquid nitrogen as a coolant in the extrusion process, a systematic methodology for the design of the cooling channel has not been proposed in literature yet. Indeed, in the industrial practice, the cooling channels are manufactured according to the designer's experience that replicate the shape of the profile as close as possible to the bearing zones, but without verified criteria to obtain an optimal cooling solution. On the other hand, the cooling performance depends on a large number of variables, such as the channel geometry (position, cross-sectional area, length, and path), inlet and outlet positions, flow rate, coolant properties and mould material thermal characteristics [19-21]. In this context, the use of numerical methods such as FEM (Finite Element Method) can be extremely useful for the analysis and selection of an optimal cooling solution in relation to the process parameters and the geometrical features of the profile. The FE process modelling is nowadays widely used in the extrusion field to predict the thermal gradient and the extrusion load during the process [22-26], as well as to predict the extrusion defects [27-28] or to optimize the die strength and lifetime [29-32]. Nevertheless, the modelling of the cooling channels effect is not consistently available in the FEM codes yet. In literature, only a previous work of Reggiani and Donati [24] is available in which a 3D numerical model of the extrusion process integrated with a 1D model of single-phase liquid nitrogen cooling is presented and validated over a simplified case study.

In this context, the aim of the present work is to innovatively test the FE modelling of the cooling effect on a real complex industrial case study taking into account the different cooling conditions: channels fully filled by liquid nitrogen or by gaseous nitrogen. The innovative numerical part of the work then consisted in the development of a model able to compute not only the effect of nitrogen liquid flow but also the gaseous condition.

The extrusion trails on the AA6060 hollow profile were performed in uncooled and cooled condition with different level of ram speed and nitrogen flow rate. The thermal data acquired by thermocouples in several locations of the die and of the backer were used to compare and to validate the numerical model. The global aim of the work is then to offer to the research community a more accurate model of the extrusion process cooled with nitrogen in order to better finalize the process optimization during the die design stage. 


\section{Experimental trials}

\subsection{Die design and liquid nitrogen cooling system}

The hollow profile depicted in Fig. 2 was selected for the experimental tests. Three parts composed the tooling set: the mandrel, the die and the backer (Fig. 1). The mandrel, with two portholes, had an external diameter of $385 \mathrm{~mm}$ and the height of $112 \mathrm{~mm}$ in the extrusion direction. The die and the backer had the same external diameter of the mandrel, but the height of $72 \mathrm{~mm}$ and $23 \mathrm{~mm}$ respectively.

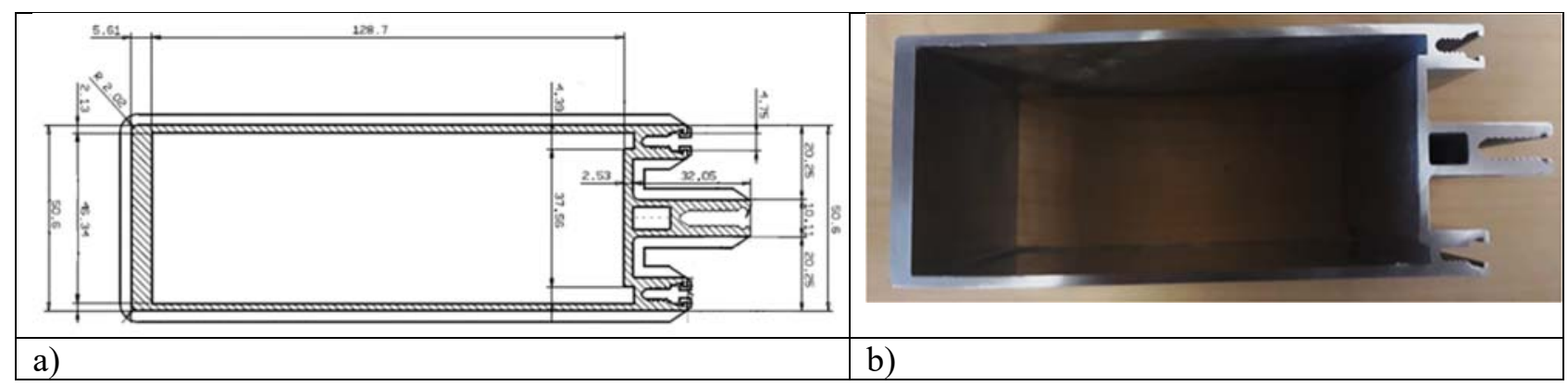

Fig.2 The hollow profile selected for the experimental tests: a) Profile drawing, b) Profile sample

The nitrogen was provided in the die through the L-shaped circular inlet channel with a diameter of $8 \mathrm{~mm}$, as reported in Fig. 3a, and it connected the nitrogen path to the planar channel, replicating the extrusion profile perimeter (Fig. 3b). The planar channel was milled at the backer face distant $33 \mathrm{~mm}$ from the bearings (Fig. 3a) with a square section (depth per width $3 \times 5 \mathrm{~mm}$ and $4 \times 6 \mathrm{~mm}$ as reported in Fig. 3b). Sixteen transferring holes (depth-per-width $2 \times 5 \mathrm{~mm}$ ) were also manufactured to lastly shift the nitrogen to the profile surface.

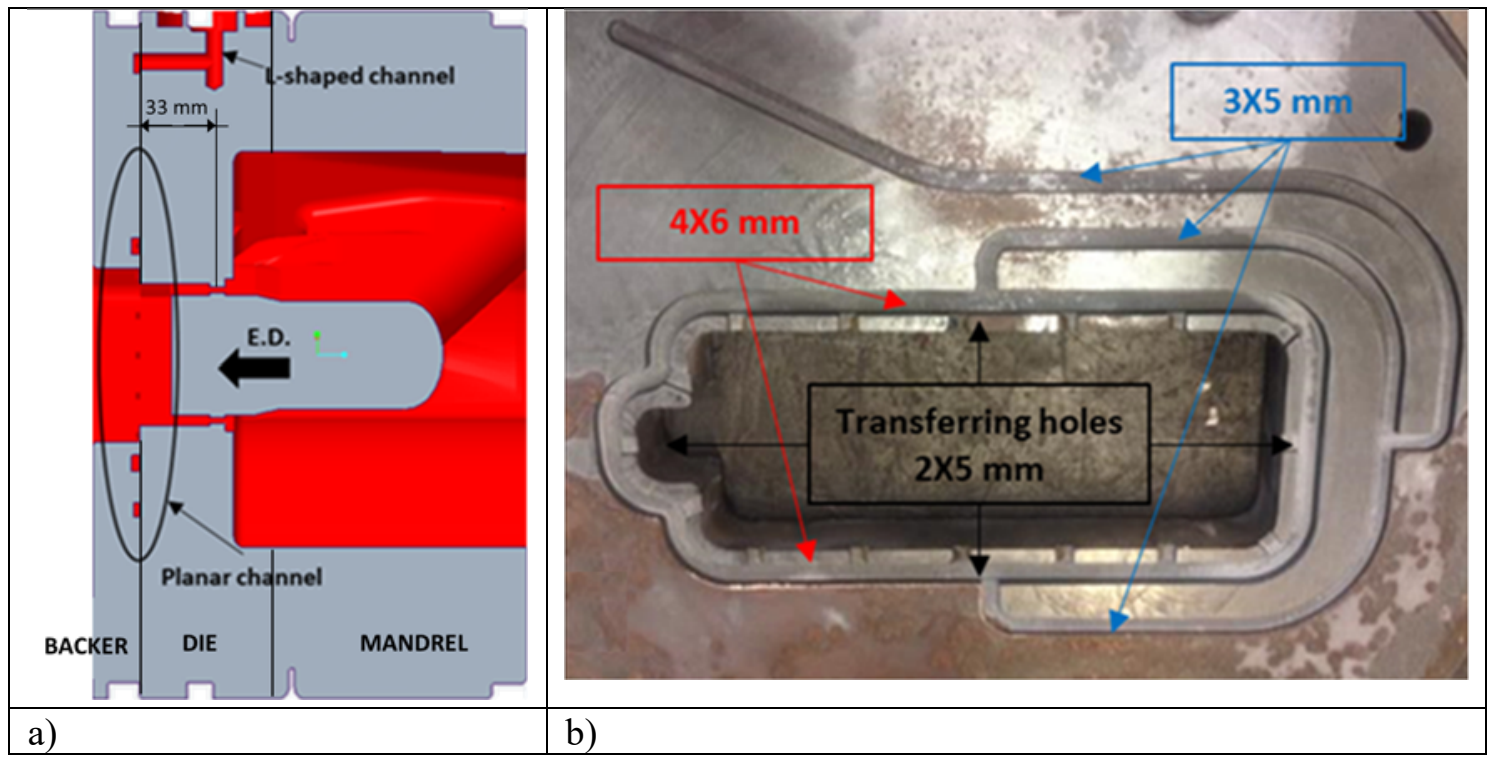

Fig.3 The cooling channel design: a) The L-shaped inlet channel; b) The rectangular section design of the planar channel

The liquid nitrogen, at a pressure of 7 bar, was stored in a large tank outside the industrial plant, with the nitrogen piped to the die through a pipeline with a length of about $100 \mathrm{~m}$ and a diameter of $15 \mathrm{~mm}$. Before entering in the die, the nitrogen flows in the sub-cooler to obtain, at the entrance of the die, a nitrogen temperature in a liquid state below $-196^{\circ} \mathrm{C}$. The maximum flow rate declared for this nitrogen plant is $80 \mathrm{Kg} / \mathrm{h}$ when the valve is fully opened. 
Eleven K-types thermocouples were used to monitor the thermal evolution during the extrusion process: six were located in the backer to follow the cooling channel path (P1 to P6 in Fig. 4b) while five were placed in the die (M3 to M7 in Fig. 4a) to control the temperature around the bearing zones. During the installation of the thermocouples, the depth of the holes in the tooling set was verified and the quotes acquired and saved (Fig.4).

In the die and the backer, an external rectangular-shaped groove was made to allow the thermocouples passage avoiding their breakage during the assembly in the ring (Fig. 5a,b). In addition, soft alloy pins were used for clamping the thermocouples further avoiding their misplacing.

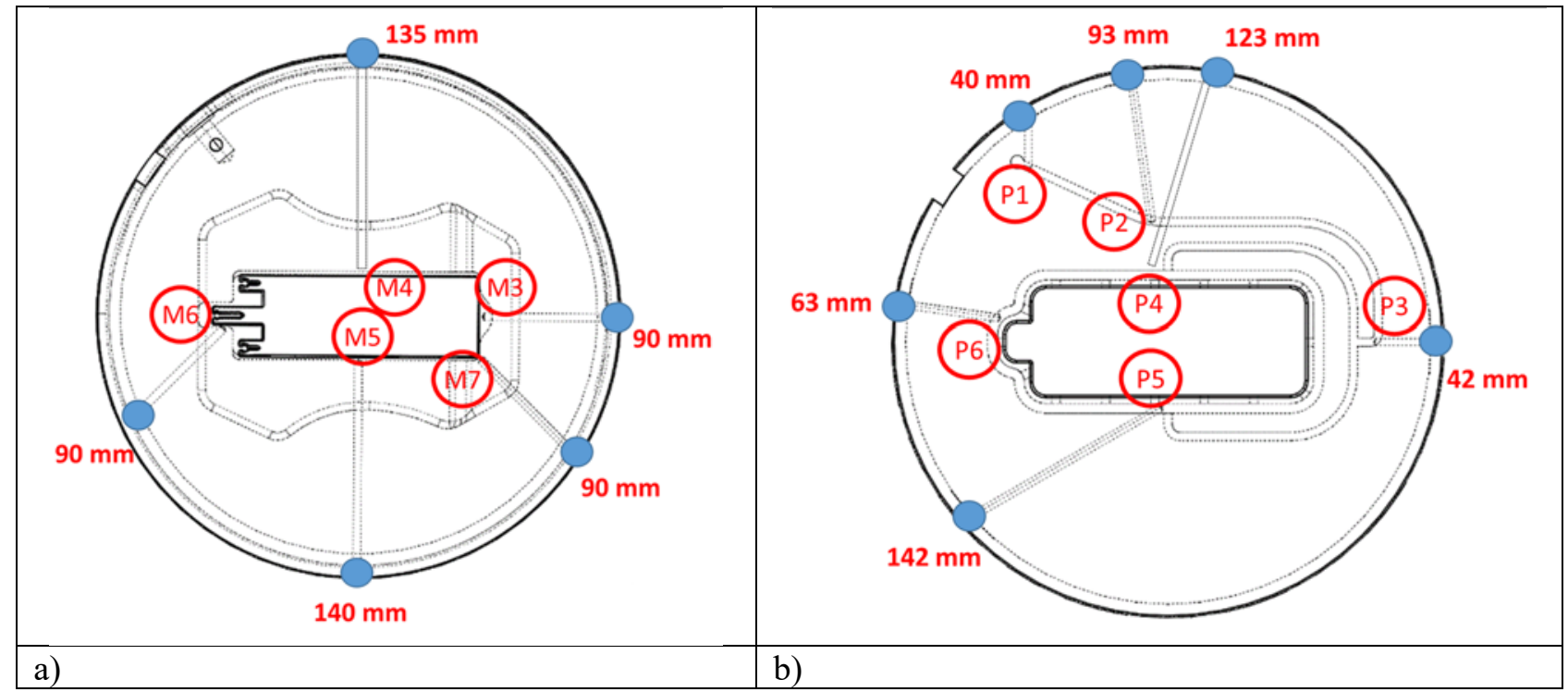

Fig.4 Positions of the thermocouples: a) Die, b) Backer; numbers report the acquired depths of the thermocouple holes.

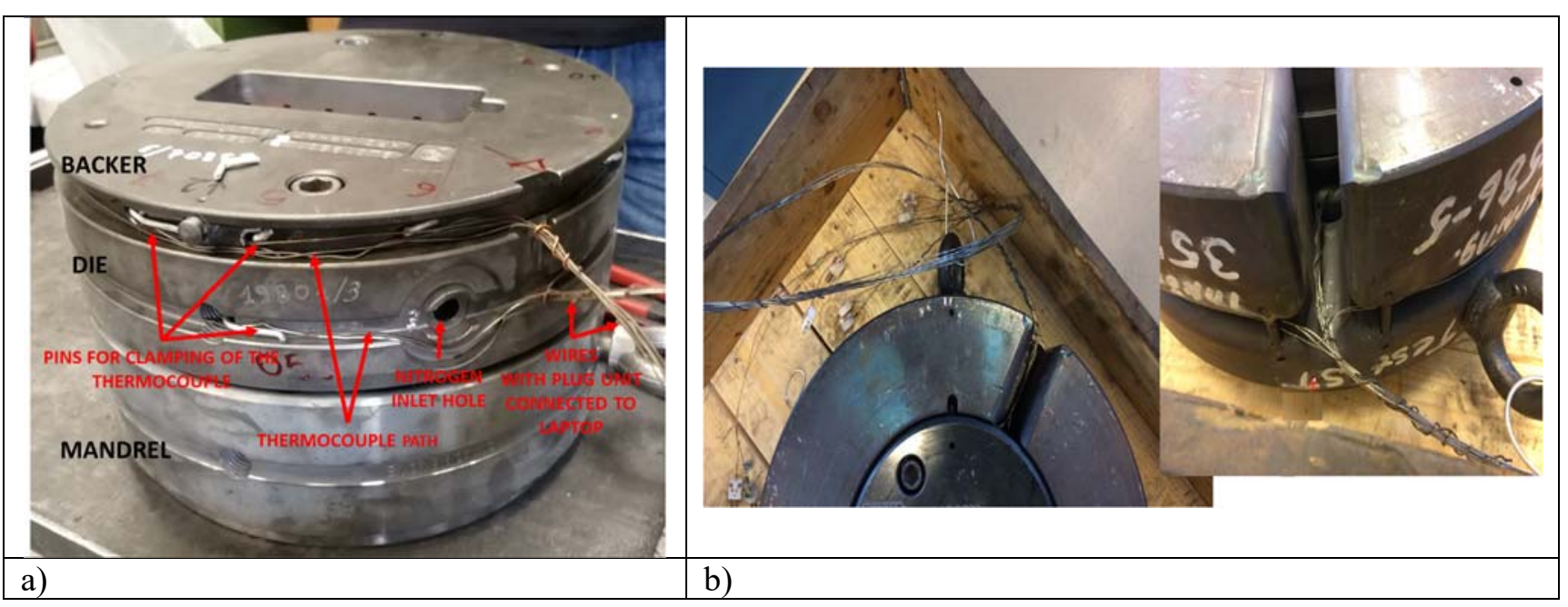

Fig.5 The installation of the thermocouples: a) in the die and backer, b) outside the external ring

\subsection{Experimental campaign}

The experimental campaign involved the extrusion of seventeen AA6060 billets in different conditions of extrusion speed and nitrogen flow rate (Fig. 6). The length and the diameter of the billets were $950 \mathrm{~mm}$ and $203 \mathrm{~mm}$, respectively. A conical taper heating from $480^{\circ} \mathrm{C}$ to $440^{\circ} \mathrm{C}$ (front-back) was applied in the billet along its axis with the pre-heating die temperature set to $520{ }^{\circ} \mathrm{C}$ and the container temperature set to $400^{\circ} \mathrm{C}$. 


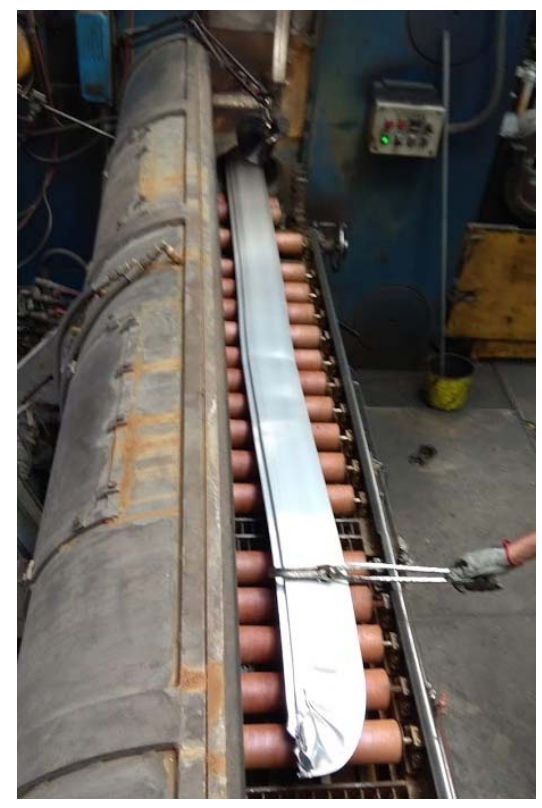

Fig.6 The extrusion of the first billet

Figure 7 reports the temperatures acquired by the thermocouples through an Agilent acquisition system connected to a laptop. The exit profile temperature was monitored at 1 meter out of the press with a Williamson contactless pyrometer (black line in Fig. 7).

Trials started with the transfer of the die assembly from pre-heating oven (set at $520^{\circ} \mathrm{C}$ ) to the press and the thermocouples connection to the acquisition system (0-250s). In Fig.7, it is clearly visible that, during this time interval, the thermocouples placed in the backer (P1-P6) already registered lower values than thermocouples placed in the mandrel (M3-M6) as consequence of the greater heat exchange of the backer with the air and the die holder in the press. The thermocouple M7 got broken during die loading and it did not acquire valid data.

At around 400s, the extrusion of the first billet started: temperatures in the die abruptly increased due to the hot aluminium flowing in the mandrel and in the die, while the temperature in the backer strongly decreased in relation to the greater heat transfer coefficient with the 'cold' press generated by extrusion load. Extrusion of billet 1 lasted up to 600 s due to the selected low ram speed $(4 \mathrm{~mm} / \mathrm{s})$ and the stop for puller clamping of the profile.

During the dwell time for the billet change (600 to 900s), the die cooled down, consequently heating up the backer that reached a thermal field close to the so called "steady-state condition of the uncooled process". From 900s, three billets were extruded at the extrusion speed of $8 \mathrm{~mm} / \mathrm{s}$ without any cooling to obtain, with billet 4 , the steady-state condition for the uncooled process. The subsequent four billets were extruded at the same velocity, but with a nitrogen flow rate of the $40 \%$ and from billet 9 to billet 12 the liquid nitrogen flow rate was increased to the maximum. From billet 13 to the last billet, the extrusion speed was increased from $8 \mathrm{~mm} / \mathrm{s}$ to $12 \mathrm{~mm} / \mathrm{s}$ maintaining the $100 \%$ of nitrogen flow rate. 


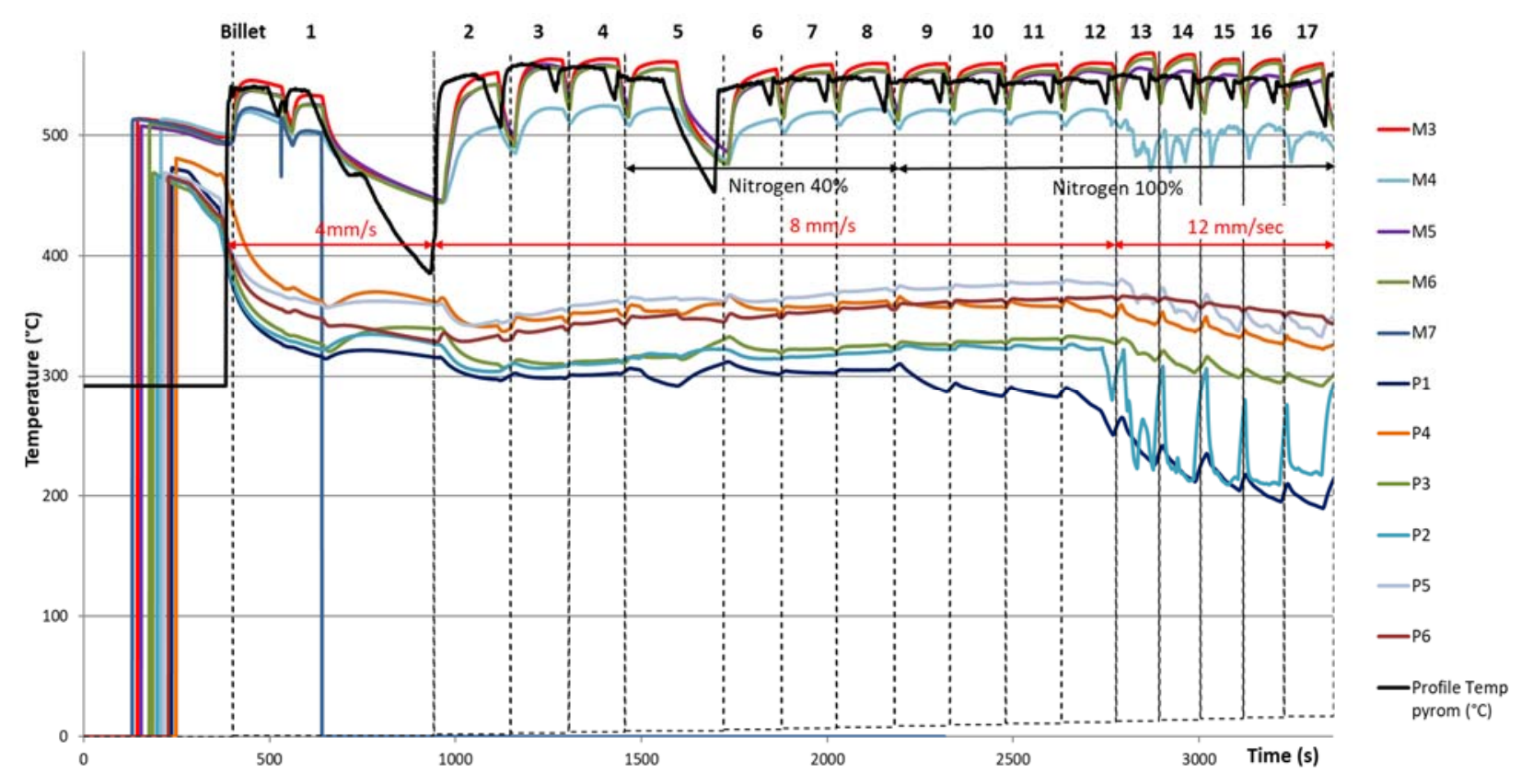

Fig.7 Temperature history of the extrusion process: Thermocouples temperature and the exit profile temperature

By analysing the thermal history of billet 4 , that represented the steady-state condition of the uncooled process, it was found an exit profile temperature of $556{ }^{\circ} \mathrm{C}$, slightly lower than the peak temperature reached in the bearing zones. Indeed, thermocouple M3, positioned nearby the vertical part of the profile without wings (Fig.4), recorded a peak temperature of $565^{\circ} \mathrm{C}$, the highest in the bearing zones. In addition, M6 (near the wings) and M5 (in the lower part of the profile) acquired a temperature only $5^{\circ} \mathrm{C}$ lower than $\mathrm{M} 3$. The lowest temperature in the bearing zones has been recorded by M4, located symmetrically with respect to M5, with a maximum value of $525^{\circ} \mathrm{C}$. In the backer, the temperatures were much lower than in the die due to the several surfaces of the backer in contact with colder parts of the press. The lower temperature was registered in $\mathrm{P} 1\left(300^{\circ} \mathrm{C}\right)$, which was located in the outer side of the backer at the entrance of the cooling channel. Thermocouples P3, P4, P5 and P6 were positioned as the corresponding thermocouples of the die, recording temperatures of $313{ }^{\circ} \mathrm{C}$, $355^{\circ} \mathrm{C}, 360^{\circ} \mathrm{C}$ and $345^{\circ} \mathrm{C}$, respectively. The thermocouple $\mathrm{P} 2$, located nearby $\mathrm{P} 1$, provided a value of $311^{\circ} \mathrm{C}$.

Billet 8 was considered the steady-state condition for an extrusion speed of $8 \mathrm{~mm} / \mathrm{s}$ and liquid nitrogen flow rate of $40 \%$. With the selected channel design, the $40 \%$ of nitrogen flow rate was not enough to promote the liquid nitrogen flow through the cooling channel that was filled with gaseous nitrogen only. This was also experimentally confirmed by the absence of ice in the external surface of the nitrogen connecting pipe. Accordingly, Fig. 7 shows no significant changes in terms of thermal gradient in all the die thermocouples M3-M6, on the profile and in P1, whilst sensors in P2-P6 even showed a slight increase, as expected by a 'warm' gas nitrogen flow in the channel.

From billet 9 , the valve of the nitrogen was opened to $100 \%$, keeping the extrusion speed at 8 $\mathrm{mm} / \mathrm{s}$. Four billets (from 9 to 12 ) were extruded in this condition. The connecting pipe started to be partially covered by ice, as confirmed by thermocouple P1 that, as first, recorded a temperature of $250{ }^{\circ} \mathrm{C}$ against $300{ }^{\circ} \mathrm{C}$ of the uncooled condition. The effect of liquid nitrogen cooling reached $\mathrm{P} 2$ during billet 10 (at around 2.500s) and reached P3 only during the extrusion of billet 12 . The data suggest a very slow replacement of gaseous nitrogen by liquid nitrogen within the channel and the coexistence of gaseous and liquid nitrogen phases in the channel. A similar effect is visible for thermocouples P4 and P5. Again, the heat subtracted in the die was negligible. For further comparison with the numerical results, discussed later in the paper, billet 12 was considered the steady-state condition for the extrusion speed of $8 \mathrm{~mm} / \mathrm{s}$ and the $100 \%$ of nitrogen flow rate. 
During the extrusion of billet 13, and subsequent billets, the extrusion speed was increased at $12 \mathrm{~mm} / \mathrm{s}$ and the nitrogen valve was kept at maximum opening. In the backer, the mixture of gaseous and liquid nitrogen begun to show a visible cooling effect throughout the channel despite the greater generation of heat related to extrusion speed increase. At the beginning of the last extrusion, the connecting pipe was completely iced and the thermocouples P1 and P2 registered the highest drop of temperature with $196{ }^{\circ} \mathrm{C}$ and $219{ }^{\circ} \mathrm{C}$ against $300{ }^{\circ} \mathrm{C}$ and $311{ }^{\circ} \mathrm{C}$ of the uncooled condition, respectively. In the die, the cooling was less prominent but now visible and effective, obtaining a drop of $23^{\circ} \mathrm{C}$ in $\mathrm{M} 4$ (from $525^{\circ} \mathrm{C}$ to $502^{\circ} \mathrm{C}$ ) and of $13^{\circ} \mathrm{C}$ in $\mathrm{M} 5$ (from $560^{\circ}$ to $547^{\circ} \mathrm{C}$ ), while, in the profile, a decrease of around $10^{\circ} \mathrm{C}$ (from $555^{\circ} \mathrm{C}$ to $545^{\circ} \mathrm{C}$ ) was achieved. It has to be reminded that, together with temperature decrease, a 50\% higher ram speed was used.

In terms of process loads, in the uncooled condition with a ram speed of $8 \mathrm{~mm} / \mathrm{s}$, a peak load of 23.3 MN (billet 4) was acquired while $24 \mathrm{MN}$ was recorded in cooled conditions (billet 12). During the extrusion of the last five billets, the combination of increased ram speed and of the low cooling effect caused a limited raise of the extrusion load (below $10 \%$ ), with a maximum registered value of 25.5 MN in billet 17.

In order to understand the behaviour of the nitrogen in the channel, it is possible to simplify the scheme as a tube with a pressure at the inlet, distributed pressure losses along the tube and outlet at atmosphere pressure (1 bar). If nitrogen enters as liquid and then changes its state in gaseous, an increase of volume of 177 times occurs thus preventing nitrogen flow. A good design of the cooling channel should lead to a condition with uniform temperatures all around the bearings but also to a short transient from gas to liquid.

Performed experimental trials highlighted the limits of the designed cooling system that was not as effective as expected. Temperatures in the backer and in the die were not uniform around the profile, with differences in the die from M3 to M4 up to $44^{\circ} \mathrm{C}$ in the cooled condition (billet 12) and up to $58{ }^{\circ} \mathrm{C}$ in the cooled condition at higher extrusion speed (billet 17) respect to the $35^{\circ} \mathrm{C}$ of the uncooled condition (billet 4). Differences became much more relevant in the backer: in billet 17, a delta of temperature of $154^{\circ} \mathrm{C}$ was found from $\mathrm{P} 1$ to $\mathrm{P} 5$ while, in billet 12 , of $88^{\circ} \mathrm{C}$ compared to $60^{\circ} \mathrm{C}$ of the uncooled condition. The nitrogen flow rate of $40 \%$ was ineffective, probably due to the excessive pressure drops generated by the channel design. Too many extrusions were needed to generate the cooling effects in the backer, also with the nitrogen flow rate set to $100 \%$. Moreover, the acquired data suggested that during the extrusion of the last billet a mixture of gas and liquid nitrogen was still flowing into the cooling channel, thus indicating that the steady-state cooled condition was not still reached. The experimental data clearly showed that the cooling effect in the die was not effective both for the unoptimized channel design and for the great distance of the channel from the bearings (Fig.3a).

In conclusion, the experimental campaign clearly showed the necessity of developing a reliable channel design criteria or numerical tools in order to gain optimal cooling conditions. Indeed, the tested design seemed initially a good solution to the press technicians, but it actually turned out to be very ineffective.

\section{Numerical modeling}

\subsection{Simulation setting of the industrial case study}

The COMSOL Multiphysics software [31] allows integrating different modules for coupled modelling of thermal, structural and fluid dynamics problems. Therefore, it is possible to model the $3 \mathrm{D}$ extrusion process integrated with a $1 \mathrm{D}$ model of the channel for nitrogen cooling as showed by the authors in a previous work [24]. 
For aluminium extrusion simulation, the COMSOL code uses a pure Eulerian approach, thus requiring the input of the billet geometry in the already-deformed configuration (Fig. 8). The figure 8a shows the meshed 3D model of the tooling set and of the aluminium parts, while the Fig. $8 \mathrm{~b}$ presents the 1D channel integrated in the tooling set for the simulation with nitrogen cooling.

Concerning the aluminium flow stress, the Zener-Hollomon (inverse sine hyperbolic) model [34] was used (Eq. 1), thus treating the hot aluminium as a non-Newtonian fluid with high viscosity related to temperature and strain rate [35]:

$$
\bar{\sigma}(T, \dot{\varepsilon})=\frac{1}{\alpha} \sinh ^{-1}\left[\frac{1}{A} \dot{\varepsilon} \exp \left(\frac{Q}{R T}\right)\right]^{\frac{1}{n}}
$$

In Tab. 1, the parameters of the flow stress model for AA6060 are reported as found in literature [36].

The mandrel, the die, and the backer were combined into a single solid tool with the aim of simplifying the computation avoiding the contact analysis. The container and the ram were replaced by equivalent thermal and fluid-dynamic boundary conditions, thus further reducing the number of components and the required computational time. For example, in the billet surface in contact with the ram, the velocity inlet condition was imposed equal to the ram speed and a temperature of $440{ }^{\circ} \mathrm{C}$ was set.

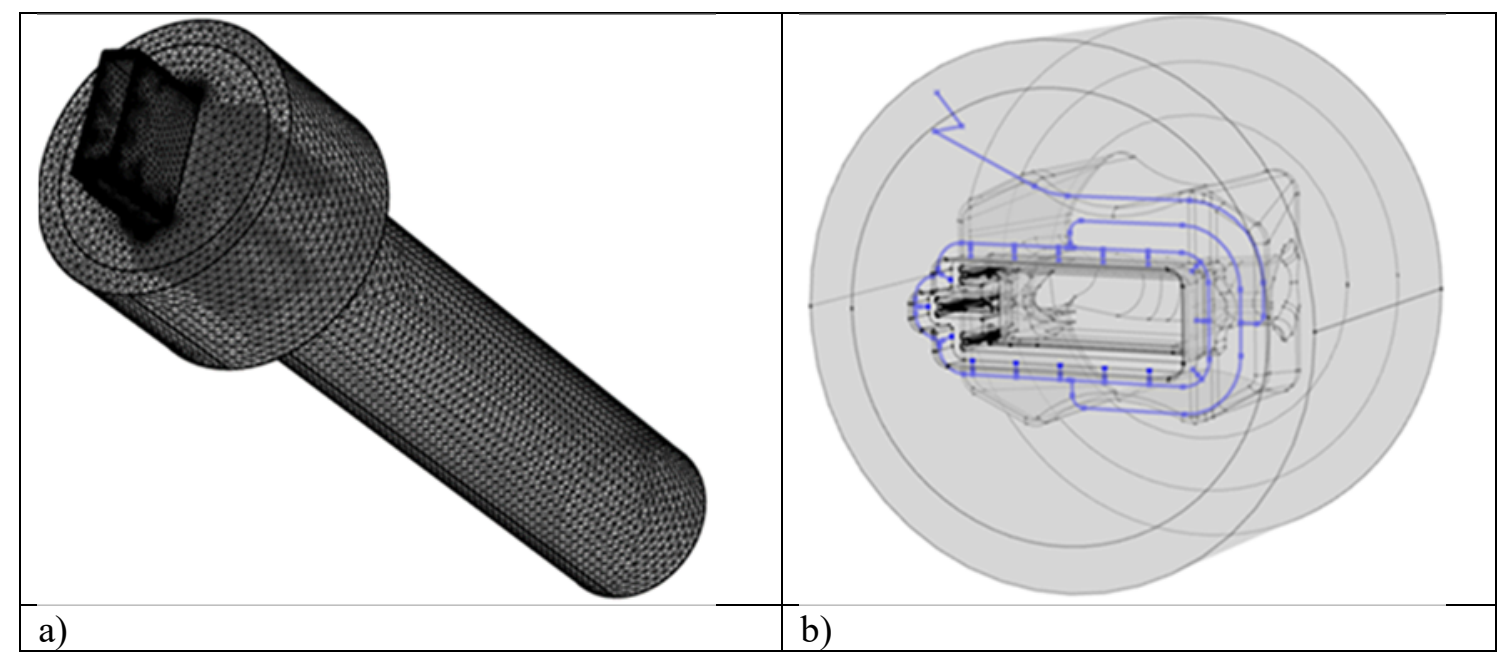

Fig.8 The geometrical model for the simulation tests: a) the billet and the die set for uncooled process, b) the tooling set combined with the $1 \mathrm{D}$ cooling channel

In the contact areas between the billet and the tooling set, a sticking friction condition was generally imposed, while in the bearing zones and in the exit profile surfaces the slip friction condition was used. Heat transfer coefficients of $11000 \mathrm{~W} / \mathrm{m}^{2 \circ} \mathrm{K}$ and $3000 \mathrm{~W} / \mathrm{m}^{2 \circ} \mathrm{K}$ were set in aluminium-totool contacts and in tool-to-tool contacts, respectively [24, 37], while $30 \mathrm{~W} / \mathrm{m}^{2 \circ} \mathrm{K}$ was set for the heat exchange with the external air. In the backer surfaces in contact with press, a heat flux with a constant temperature of $280{ }^{\circ} \mathrm{C}$ was imposed, experimentally suggested by the temperature of $300{ }^{\circ} \mathrm{C}$ registered by $\mathrm{P} 1$ in the steady-state uncooled condition.

Simulations were performed without any cooling for comparison with billet 4 , with the model for gaseous nitrogen only as comparison with billet 12 and with the model for liquid nitrogen only as comparison with billet 17 . Even if the phase change is not considered in this model, the analysis of the nitrogen thermal map allows to locate the shift of phase of the nitrogen in the channel. Transient simulations were performed in order to represent the whole extrusion time experimentally processed. 
The process parameters were set to replicate the experimental setting and they are reported in Tab. 2. Specifically, the uncooled simulation used, as initial values, the initial conditions of billet 1 , while the cooled simulations both started with the steady-state condition obtained in the uncooled simulation (billet 4). In both simulations with nitrogen cooling, the same pressure gradient was imposed between the inlet and the outlets of the channels and equal to the amount needed to get 80 $\mathrm{Kg} / \mathrm{h}$ of liquid nitrogen flow rate. In Tab. 2, the physical properties of liquid and gas nitrogen at the boiling point at room pressure $\left(-196^{\circ} \mathrm{C}\right)[18]$ are also reported.

Table 1. Flow stress parameters of Zener-Hollomon model for AA 6060.

\begin{tabular}{ll}
\hline Flow stress parameters & $\mathbf{A A 6 0 6 0}$ \\
\hline Q parameter of Zener-Hollomon model & $161 \mathrm{KJ} / \mathrm{mol}$ \\
A parameter of Zener-Hollomon model & $7.6301 * 10^{10} 1 / \mathrm{s}$ \\
$\mathrm{n}$ parameter of Zener-Hollomon model & 4.67 \\
$a$ parameter of Zener-Hollomon model & $0.0351 / \mathrm{MPa}$ \\
\hline
\end{tabular}

Table 2. Process parameters and nitrogen properties for all simulations.

\begin{tabular}{|c|c|c|c|}
\hline Process Parameters & $\begin{array}{c}\text { Uncooled } \\
\text { Process }\end{array}$ & Gas nitrogen cooling & $\begin{array}{l}\text { Liquid nitrogen } \\
\text { cooling }\end{array}$ \\
\hline Billet Temperature & $480^{\circ} \mathrm{C}$ & $480^{\circ} \mathrm{C}$ & $480^{\circ} \mathrm{C}$ \\
\hline Die Temperature & $510^{\circ} \mathrm{C}$ & $\begin{array}{l}\text { Initial value steady state } \\
\text { uncooled simulation } \\
\text { (end of Billet } 4)\end{array}$ & $\begin{array}{l}\text { Initial value steady state } \\
\text { uncooled simulation } \\
\text { (end of Billet } 4)\end{array}$ \\
\hline Container Temperature & $430^{\circ} \mathrm{C}$ & $430^{\circ} \mathrm{C}$ & $430^{\circ} \mathrm{C}$ \\
\hline Ram Temperature & $440^{\circ} \mathrm{C}$ & $440^{\circ} \mathrm{C}$ & $440^{\circ} \mathrm{C}$ \\
\hline $\begin{array}{l}\text { Temperature of backer surfaces in } \\
\text { contact with press }\end{array}$ & $280^{\circ} \mathrm{C}$ & $280^{\circ} \mathrm{C}$ & $280^{\circ} \mathrm{C}$ \\
\hline Ram Speed & $8 \mathrm{~mm} / \mathrm{s}$ & $8 \mathrm{~mm} / \mathrm{s}$ & $12 \mathrm{~mm} / \mathrm{s}$ \\
\hline Inlet nitrogen Temperature & - & $-196^{\circ} \mathrm{C}$ & $-196^{\circ} \mathrm{C}$ \\
\hline Nitrogen flow rate & - & $6.04 \mathrm{Kg} / \mathrm{h}$ & $80 \mathrm{Kg} / \mathrm{h}$ \\
\hline $\begin{array}{l}\text { Surface roughness of the channel } \\
\text { (e) }\end{array}$ & - & $0.046 \mathrm{~mm}$ & $0.046 \mathrm{~mm}$ \\
\hline Nitrogen density $(\rho)$ & - & $4.5565 \mathrm{~kg} / \mathrm{m}^{3}$ & $806.59 \mathrm{~kg} / \mathrm{m}^{3}$ \\
\hline $\begin{array}{l}\text { Nitrogen heat capacity at constant } \\
\text { pressure }\left(C_{p}\right)\end{array}$ & - & $1.1231 \mathrm{~J} / \mathrm{g} * \mathrm{~K}$ & $2.0410 \mathrm{~J} / \mathrm{g} * \mathrm{~K}$ \\
\hline Nitrogen thermal conductivity $(\mathrm{k})$ & - & $0.007 \mathrm{~W} / \mathrm{m} * \mathrm{~K}$ & $0.14605 \mathrm{~W} / \mathrm{m} * \mathrm{~K}$ \\
\hline
\end{tabular}

\subsection{D Nitrogen cooling modelling}

The 1D cooling model approximates the pipe flow profile as mono-dimensional thus reducing the calculation to the mid-line path $[20,33]$. In addition, it is possible to set the geometrical shape of the channel cross section for the evaluation of the fluid dynamic variables (Reynolds number, pressure drop, etc). The model calculates the pressure and velocity of an incompressible or weakly 
compressible fluid (phase change is not considered), by solving the continuity and momentum equations (eqns.2,3) reported in the following:

$$
\begin{gathered}
\frac{\partial A \rho}{\partial t}+\nabla \cdot(A \rho u)=0 \\
\rho \frac{\delta u}{\delta t}=-\nabla p-f_{D} \frac{\rho}{2 d_{h}} u|u|
\end{gathered}
$$

The second term on the right-hand side of Eq. 3 accounts for pressure drop due to viscous shear. The pipe flow physics uses the Churchill friction model to compute the Darcy factor $\mathrm{f}_{\mathrm{D}}$, that it is valid for laminar flow, turbulent flow and the transition region. The Churchill friction model is given by Eq.4, where $A$ and $B$ are the empirical coefficients that depend on the Reynolds number $\left(\mathrm{Re}_{\mathrm{e}}\right)$ and the surface roughness divided by diameter of the pipe, $e / d_{h}$.

$$
\begin{gathered}
f_{D}=8 \cdot\left[\left(\frac{8}{R e}^{12}(A+B)^{-1.5}\right)^{\frac{1}{12}}\right] \\
A=\left[-2.457 \cdot \ln \left(\left(\frac{7^{0.9}}{R e}\left(\frac{e}{d_{h}}\right)\right)\right]^{16}\right. \\
B=\left(\frac{37530}{R e}\right)^{16}
\end{gathered}
$$

Concerning the prediction of the thermal field in the channel and of the thermal interaction between the nitrogen and the die, the heat transfer equation is:

$$
\rho A C_{p} \frac{\partial T}{\partial t}+\rho A C_{p} u \cdot \nabla T=\nabla \cdot A k \nabla T+f_{D} \frac{\rho A}{2 d_{h}} u^{3}+Q_{w a l l}
$$

where $C_{p}$ is the heat capacity at constant pressure, $T$ the nitrogen cooling temperature and $k$ the thermal conductivity. The second term on the right-hand side corresponds to the heat dissipated due to internal friction in the fluid. In addition, $Q_{\text {wall }}$ is a source term that accounts for the heat exchange with the surrounding die:

$$
\begin{gathered}
Q_{\text {wall }}=h Z\left(T_{2}-T\right) \\
\rho_{2} C_{p 2} \frac{\partial T_{2}}{\delta t}=\nabla \cdot k \nabla T 2
\end{gathered}
$$

In the Eq. $8, Z$ is the perimeter of the pipe, $T_{2}$ is the temperature calculated in each point of the die, while $h$ is the heat transfer coefficient. The latter depends on the physical properties of the fluid and on the nature of the flow and it is calculated from the Nusselt number $\left(N_{u}\right)$ :

$$
h=N u \frac{k}{d_{h}}
$$

As can be seen, the $h$ is not considered as constant along the cooling path, differently from what frequently imposed in the published literature.

The use of a $1 \mathrm{D}$ approach is preferred to $3 \mathrm{D}$ approaches, in order to avoid an excessive increase in the computational time without decreasing the reliability and the accuracy of the simulation. 
The suggested approach then perfectly matches the requirement of supporting the die design phase in an industrial framework, even accounting for the possibility to rapidly modify the cooling channel design parameters, the position and the shape of the channels and also its cross-section for the achievement of the optimal solution.

\section{Comparison between the numerical and the experimental results}

The numerical predictions were compared with the experimental data in terms of temperatures and extrusion load. Figures 9 and 10 show the computed thermal map of the die and the backer in the thermocouple mid-plane for the three different cooling conditions.

In the simulation without cooling, the thermal map of Fig. 9a shows a range of temperatures around $560{ }^{\circ} \mathrm{C}$ nearby the bearings while the simulation with gas nitrogen cooling showed almost no temperature changes around the bearings (Fig. 9b) and a limited drop of temperatures towards the external surface of the die only. The simulated liquid nitrogen cooling was more effective, displaying the greater temperature drop around M4, M5 and M7, while a minor effect nearby M3 and M6.

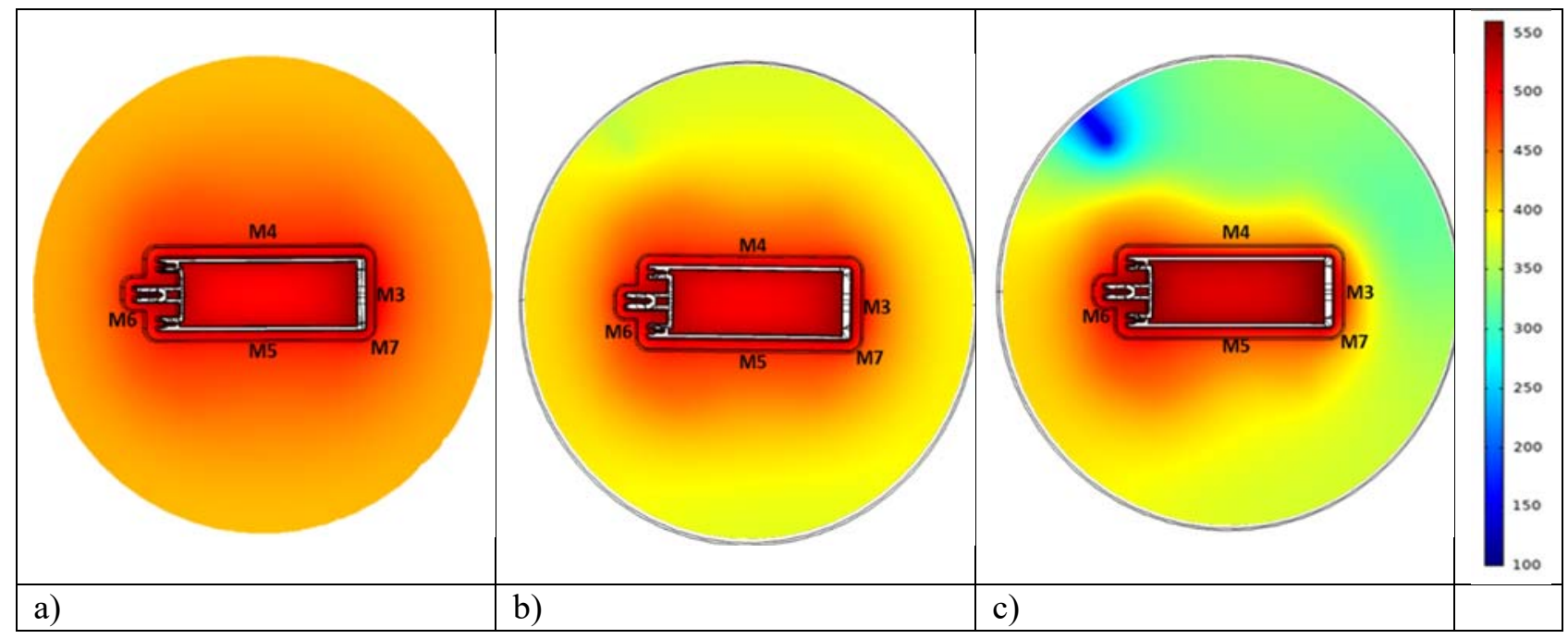

Fig.9 Thermal map of the die after 600 s of simulation: a) uncooled, b) gas cooled process, c) liquid cooled process

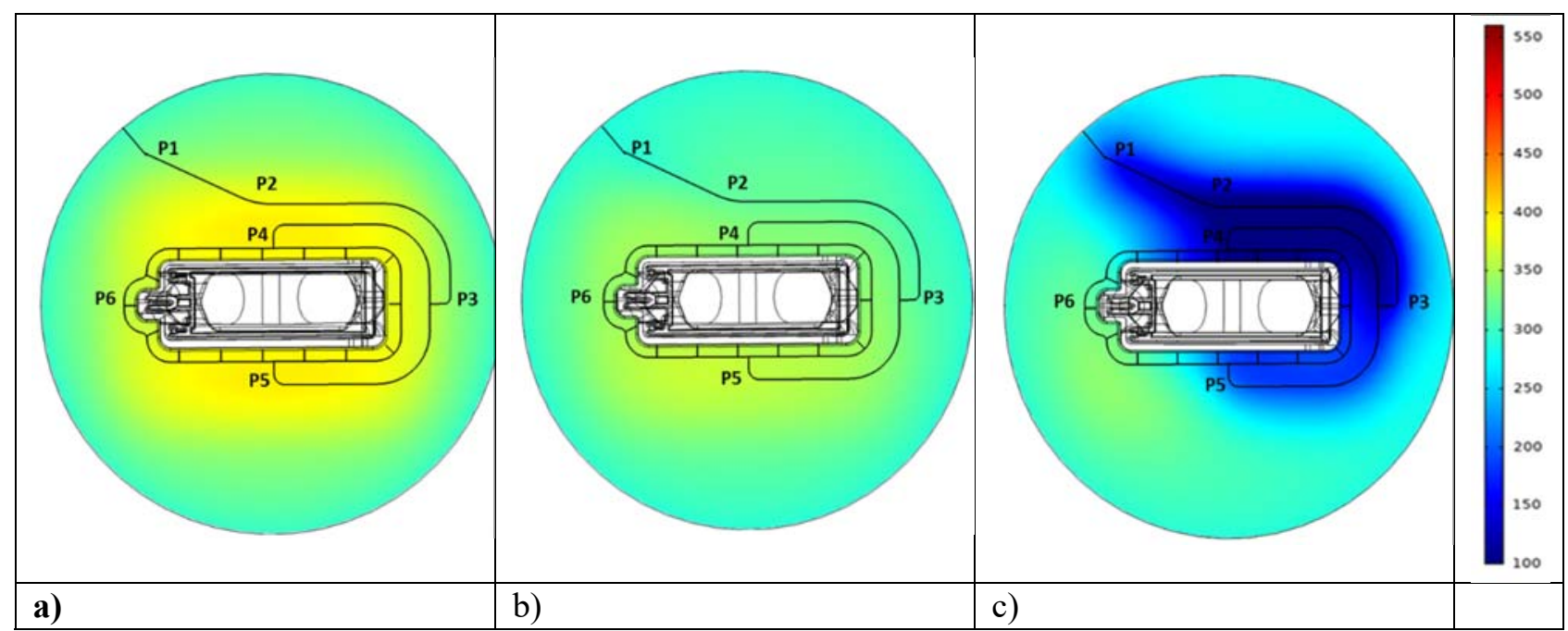

Fig.10 Thermal map of the backer after $600 \mathrm{~s}$ of simulation: a) uncooled, b) gas cooled process, c) liquid cooled process

In the backer, the thermal map of the gas cooled condition showed a small cooling effect, obtaining the maximum drop of temperatures of about $20^{\circ} \mathrm{C}$ in the region around $\mathrm{P} 1$. The liquid 
nitrogen underlined a greater cooling effect, made clear by the deep blue region across the channel. However, the cooling turned out to be less effective around P5 and negligible nearby P6, thus clearly pointing out the limits of the channel design.

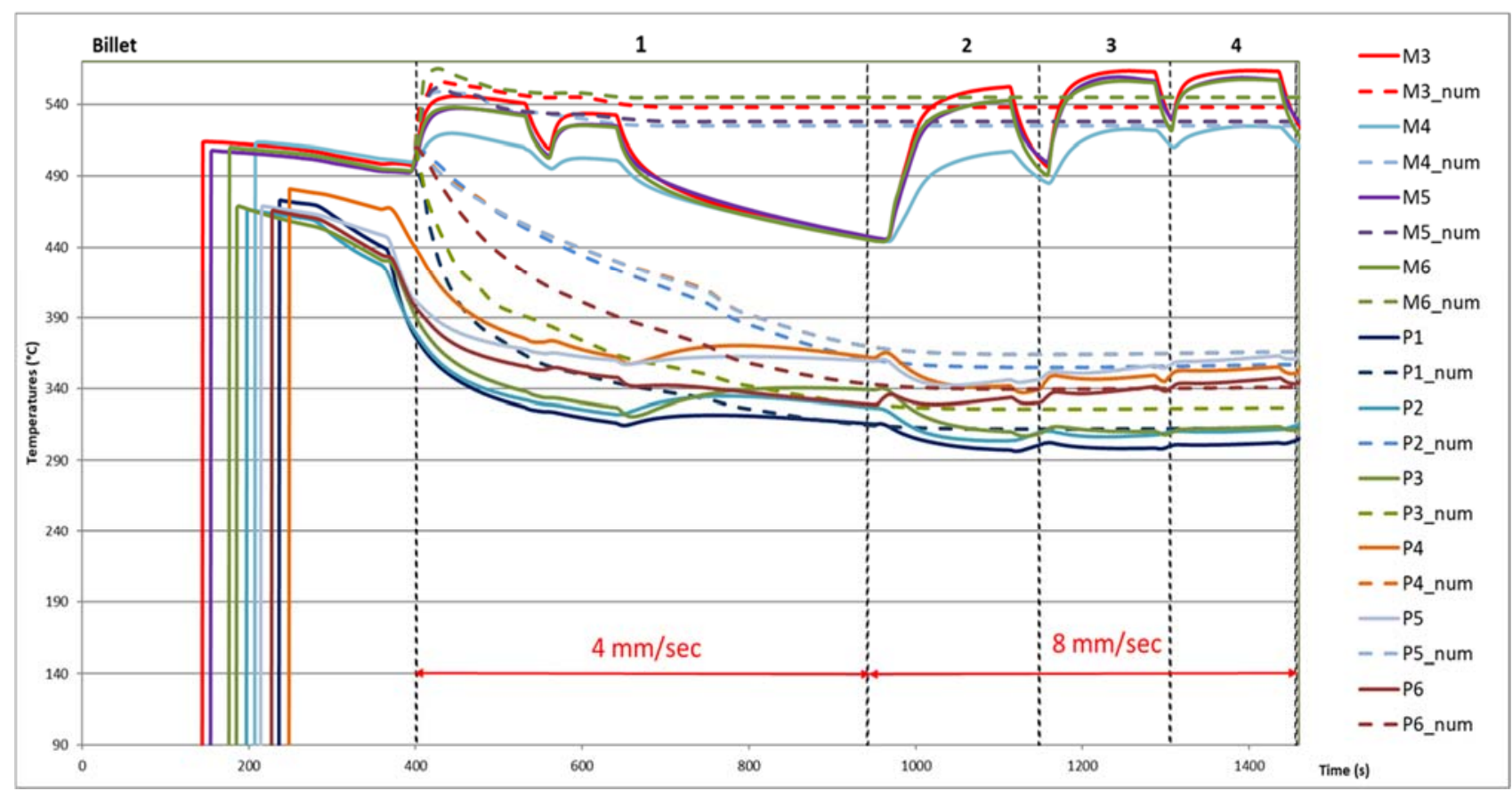

Fig.11 Temperature history of the extrusion process: Experimental-numerical comparison without cooling

In Fig. 11, the experimental data of all the thermocouples were overlapped to the values computed by the simulation in the uncooled condition (billets 1 to 4). The Eulerian approach considers the billet as a continuous fluid that flows within the container and the die; thus, during the transient simulation, the model simulated the extrusion of a single virtual billet for $600 \mathrm{~s}$. For this reason, numerical results in the die (M3-M6) showed an initial peak of temperatures generated by the billet in deformation then, after the transitory, the temperatures reached a steady-state condition. On the contrary, the experimental results showed a peak of temperatures and a cooling down during each billet change. Similar considerations can be drawn for backer locations (P1-P6) unless the initial thermal increase not detected in both experimental and numerical data.

The numerical results of the steady-state simulation in the backer showed a good matching with experimental data (error below 4,5\%), with an overestimation only in P2 $\left(357^{\circ} \mathrm{C}\right.$ num. against $311^{\circ} \mathrm{C}$ exp.).

The numerical steady-state condition provided a drop of temperatures with respect to the initial transitory, related to the simulated billet cooling in the container. Indeed, the boundary condition in the billet replicated a heat flux with constant temperature equal to the container temperature $\left(430^{\circ} \mathrm{C}\right)$. This condition cooled excessively the "long virtual billet", while the preheated temperature of the real billets was higher. However, the maximum numerical underestimation of 32 ${ }^{\circ} \mathrm{C}$ registered in $\mathrm{M} 5\left(528^{\circ} \mathrm{C}\right.$ against $\left.560^{\circ} \mathrm{C}\right)$ did not affect the reliability of the predicted results.

In Tab.3 and 4, the experimental-numerical comparisons for the backer and the die in the steady-state uncooled condition are reported. The accuracy of the numerical predictions was assessed by the errors always below the $6 \%$ in all thermocouples except for P2 (14.8\%). In terms of extrusion load, a peak of $20.5 \mathrm{MN}$ was predicted against $23.3 \mathrm{MN}$ experimentally acquired, with an error of the $12 \%$. 
Table 3. Comparison between the experimental acquired temperatures in the backer and the predicted numerical results (Billet 4)

\begin{tabular}{|c|c|c|c|c|c|c|c|}
\hline \multirow[t]{2}{*}{ Billet 4} & \multicolumn{6}{|c|}{ Thermocouples Temperature $\left[{ }^{\circ} \mathrm{C}\right]$} & \multirow[t]{2}{*}{ Cooling } \\
\hline & P1 & $\mathbf{P 2}$ & P3 & $\mathbf{P 4}$ & P5 & P6 & \\
\hline Experimental & 300 & 311 & 313 & 355 & 360 & 345 & NO \\
\hline Numerical & 313 & 357 & 327 & 366 & 366 & 341 & NO \\
\hline Err\% & $+4.3 \%$ & $+14.8 \%$ & $+4.5 \%$ & $+3.1 \%$ & $+1.7 \%$ & $-1.2 \%$ & \\
\hline
\end{tabular}

Table 4. Comparison between the experimental acquired temperatures in the die and the predicted numerical results (Billet 4)

\begin{tabular}{|c|c|c|c|c|c|c|c|}
\hline \multirow[t]{2}{*}{ Billet 4} & \multicolumn{5}{|c|}{ Thermocouples Temperature $\left[{ }^{\circ} \mathrm{C}\right]$} & \multirow[t]{2}{*}{ Profile Exit $\mathbf{T}\left[{ }^{\circ} \mathbf{C}\right]$} & \multirow[t]{2}{*}{ Cooling } \\
\hline & M3 & M4 & M5 & M6 & M7 & & \\
\hline Experimental & 565 & 525 & 560 & 560 & & 556 & NO \\
\hline Numerical & 538 & 525 & 528 & 545 & 525 & 549 & NO \\
\hline Err\% & $-4,8 \%$ & $0 \%$ & $-5,7 \%$ & $-1,3 \%$ & & $-1,3 \%$ & \\
\hline
\end{tabular}

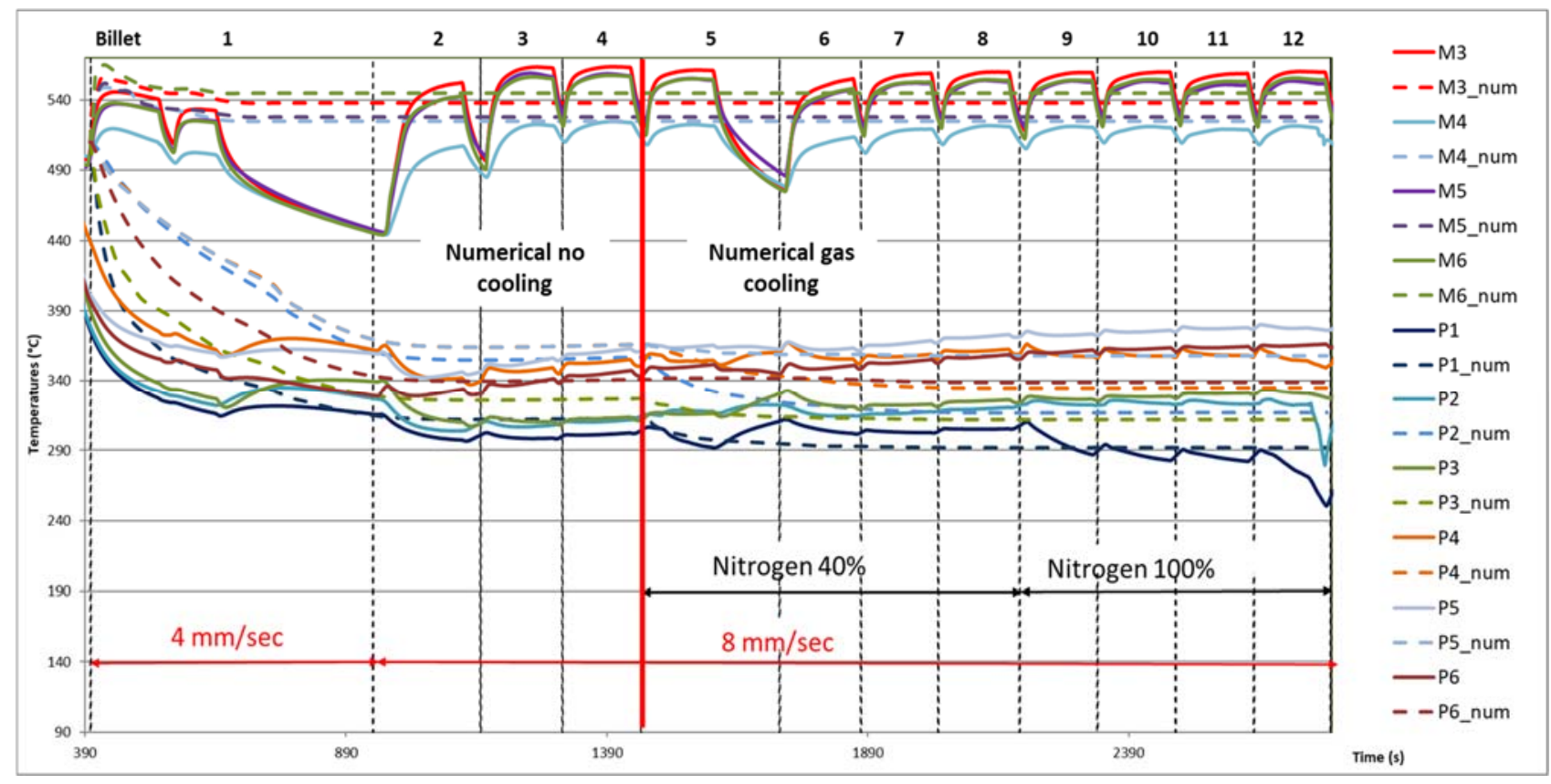

Fig.12 Temperature history of the extrusion process: Experimental-numerical comparison in the gaseous cooled condition

In Fig. 12, the simulation of gaseous nitrogen cooling was compared to the experimental results. The numerical computation started from the steady-state uncooled thermal condition (end of billet 4) with gaseous model, $100 \%$ valve opening and $8 \mathrm{~mm} / \mathrm{s}$ of ram speed. Results are plotted up to billet 12 , when liquid nitrogen started providing a visible cooling effect. Indeed, the connecting 
pipe started to be covered by ice only from billet 12 while, during the previous extrusions, only gas nitrogen was flowing within the channel.

In the die, the numerical outcomes matched the experimental cooling inefficiency, further underlining the minor cooling effectiveness of gas nitrogen.

In the backer, during the extrusion of billets 5 to 11 , a good accuracy of the numerical model was found for locations P1 to P3 whilst for locations P4 to P6 the simulation provided a slight underestimation of the temperatures. However, a better matching was achieved in locations P2 to P4 if data at the end of the billet 12 are analysed, with a numerical overestimation of the experimental temperature in P1 and an underestimation in P5 and P6. The different matching is related to the time history of the nitrogen phase evolution. In billet 5, the gaseous nitrogen had an effect on P1 to P3 only, while the other locations behaved like in uncooled conditions. In billet 12, the liquid nitrogen started flowing in P1, thus affecting also P2 at the end of billet 12 . The remaining locations were affected by the effect of gaseous-liquid mixture with a drop of temperatures during the extrusion of billet 12. Table 6 reports the comparison of simulated and experimental temperatures at the middle of billet 12 with errors always below the $8 \%$. In terms of extrusion load, a simulated peak value of 21 $\mathrm{MN}$ was obtained against $24 \mathrm{MN}$ experimentally acquired (error of $12.5 \%$ ).

Table 5. Comparison between the experimental acquired temperatures in the backer and the predicted numerical results (Billet 12)

Billet 12

Thermocouples Temperature $\left[{ }^{\circ} \mathrm{C}\right]$

Cooling

\begin{tabular}{cccccccc}
\hline & P1 & P2 & P3 & P4 & P5 & P6 & \\
\hline Experimental & 272 & 325 & 329 & 351 & 360 & 347 & Gaseous \\
\hline Numerical & 292 & 317 & 312 & 335 & 358 & 339 & Gaseous \\
\hline \%Err & $+7.4 \%$ & $-2.5 \%$ & $-5.2 \%$ & $-4,6 \%$ & $-0.6 \%$ & $-2.3 \%$ & \\
\hline
\end{tabular}

Table 6. Comparison between the experimental acquired temperatures in the backer and the predicted numerical results (Billet 12)

\begin{tabular}{|c|c|c|c|c|c|c|c|}
\hline \multirow[t]{2}{*}{ Billet 12} & \multicolumn{5}{|c|}{ Thermocouples Temperature $\left[{ }^{\circ} \mathrm{C}\right]$} & \multirow[t]{2}{*}{ Profile Exit $\mathbf{T}\left[{ }^{\circ} \mathrm{C}\right]$} & \multirow[t]{2}{*}{ Cooling } \\
\hline & M3 & M4 & M5 & M6 & M7 & & \\
\hline Experimental & 560 & 516 & 552 & 554 & & 545 & Gaseous \\
\hline Numerical & 538 & 525 & 528 & 545 & 525 & 548 & Gaseous \\
\hline$\%$ Err & $-3.9 \%$ & $+1.7 \%$ & $-4.3 \%$ & $-1.6 \%$ & & $+0.6 \%$ & \\
\hline
\end{tabular}




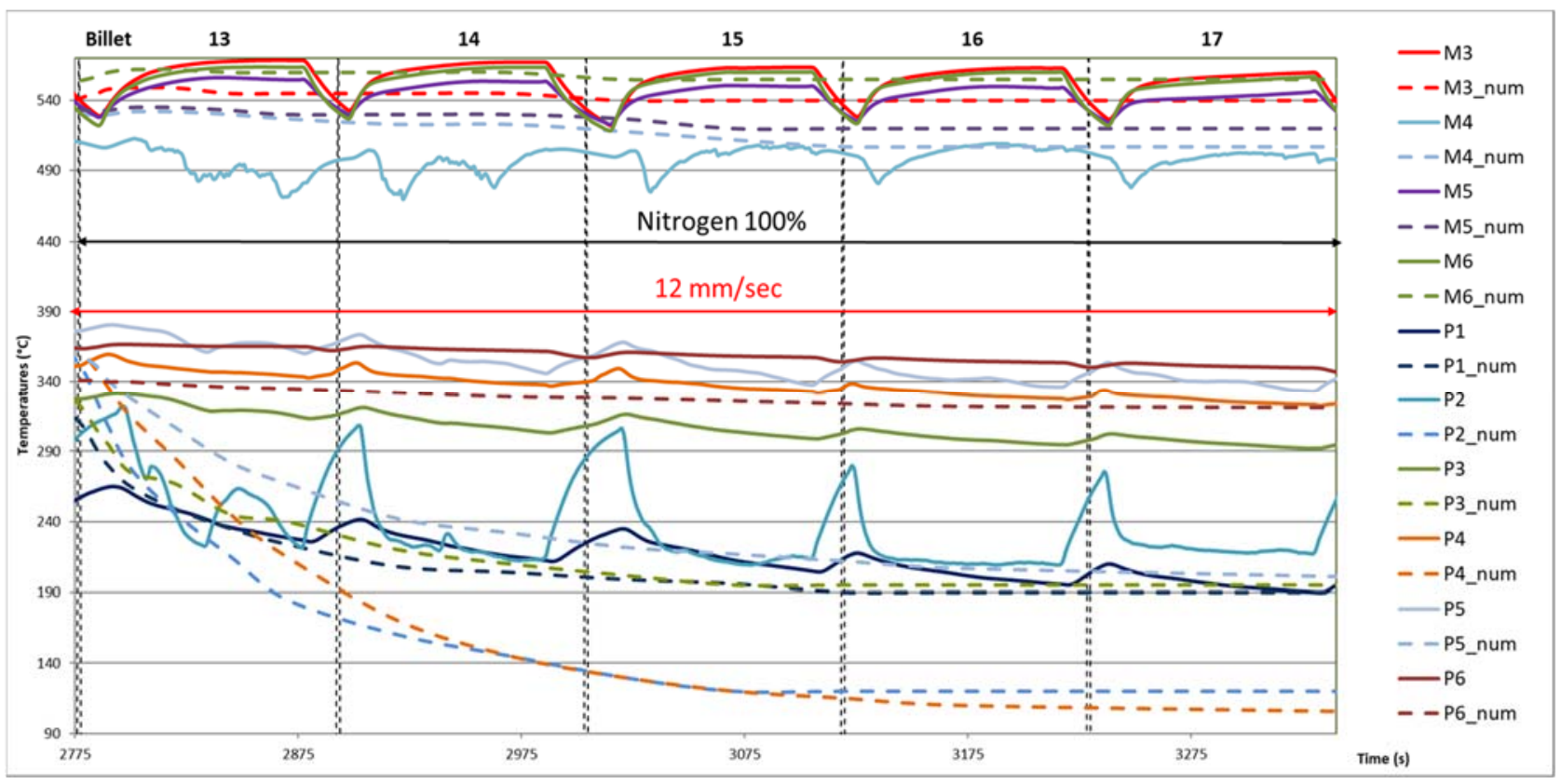

Fig.13 Temperature history of the extrusion process: Experimental-numerical comparison in the liquid cooled condition

In Fig. 13, the simulation data of the liquid cooled condition (100\% valve opening and an extrusion ram speed of $12 \mathrm{~mm} / \mathrm{s}$ ) were compared with the experimental data. Results are plotted for billets 13 to 17 .

In the die, the increase of ram speed caused an initial raise of temperature in all thermocouples, as visible during the processing of billet 13. Liquid nitrogen cooling generated a decrease of temperatures in M4 and M5, while a negligible cooling was detected in the other thermocouples, in good agreement with the experimental results.

In the backer, the numerical cooling was more effective than in the experimental trials, with a good temperature matching only for P1 due to the presence of liquid-gas mixture nitrogen within the whole channel (from P2 to P5). Finally, a good correlation was also found for P6 with a negligible temperature decrease both in the numerical and the experimental results.

Tables 7 and 8 reports in detail data for billet 17 . In the backer, a peak error of $-67.8 \%$ was found in P4 temperature prediction, but in P1 and in P6 the error was of 3.1\% and $8.3 \%$, respectively. In the die, errors were always below $5 \%$. In terms of extrusion load, both in the numerical prediction and in the experimental results, the increase of loads remained under $10 \%$ (numerically, from 20.5 $\mathrm{MN}$ of billet 4 to $22 \mathrm{MN}$ of billet 17, experimentally from $23.3 \mathrm{MN}$ to $25.5 \mathrm{MN}$ ).

Table 7. Comparison between the experimental acquired temperatures in the backer and the predicted numerical results (Billet 17)

\begin{tabular}{|c|c|c|c|c|c|c|c|}
\hline \multirow[t]{2}{*}{ Billet 17} & \multicolumn{6}{|c|}{ Thermocouples Temperature $\left[{ }^{\circ} \mathrm{C}\right]$} & \multirow[t]{2}{*}{ Cooling } \\
\hline & P1 & $\mathbf{P 2}$ & P3 & P4 & P5 & P6 & \\
\hline Experimental & 196 & 219 & 296 & 326 & 340 & 350 & Liquid \\
\hline Numerical & 190 & 120 & 195 & 105 & 200 & 321 & Liquid \\
\hline$\%$ Err & $-3.1 \%$ & $-45.2 \%$ & $-34.1 \%$ & $-67.8 \%$ & $-41.2 \%$ & $-8,3 \%$ & \\
\hline
\end{tabular}


Table 8. Comparison between the experimental acquired temperatures in the backer and the predicted numerical results (Billet 17)

\begin{tabular}{|c|c|c|c|c|c|c|c|}
\hline \multirow[t]{2}{*}{ Billet 17} & \multicolumn{5}{|c|}{ Thermocouples Temperature $\left[{ }^{\circ} \mathrm{C}\right]$} & \multirow[t]{2}{*}{ Profile Exit $\mathbf{T}\left[{ }^{\circ} \mathbf{C}\right]$} & \multirow[t]{2}{*}{ Cooling } \\
\hline & M3 & M4 & M5 & M6 & M7 & & \\
\hline Experimental & 560 & 502 & 547 & 557 & & 541 & Liquid \\
\hline Numerical & 540 & 507 & 520 & 555 & 490 & 555 & Liquid \\
\hline$\%$ Err & $-3.6 \%$ & $+1.0 \%$ & $-4.9 \%$ & $-0.4 \%$ & & $+2.6 \%$ & \\
\hline
\end{tabular}

Finally, even if the numerical model of nitrogen cooling does not consider the phase change, the analysis of the nitrogen temperature can provide information about nitrogen phase. With the assumption that all pressure drops in the channel are negligible, the range of pressure within the channel is about 3-4 bars and, in this condition, the boiling temperature of nitrogen is about $-186{ }^{\circ} \mathrm{C}$ (Fig. 14) [18]. The information obtained by the liquid nitrogen thermal map (Figs. 15a, b) of billet 12 confirmed the presence of a big amount of gas along the channel. As can be deduced from the Fig. 15a, the temperature is higher than the boiling temperature along the channel, with values of $-50{ }^{\circ} \mathrm{C}$ nearby P4 and P5 and of about $10^{\circ} \mathrm{C}$ nearby P6. Figure $15 \mathrm{~b}$ shows in red all the points of the cooling path with temperatures higher than the boiling point at 3 bars of pressure. Only nearby the inlet channel, the obtained temperatures suggested the presence of liquid nitrogen as also experimentally evidenced.

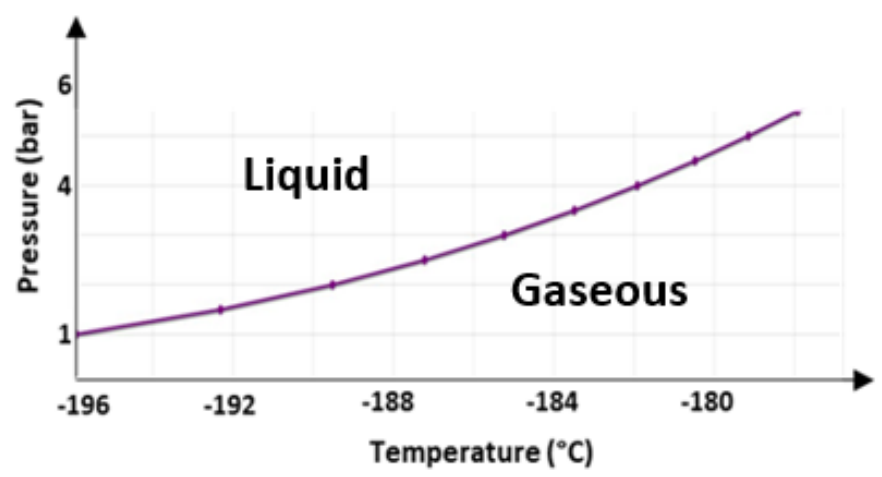

Fig.14 Boiling point of liquid nitrogen according to the operating pressure

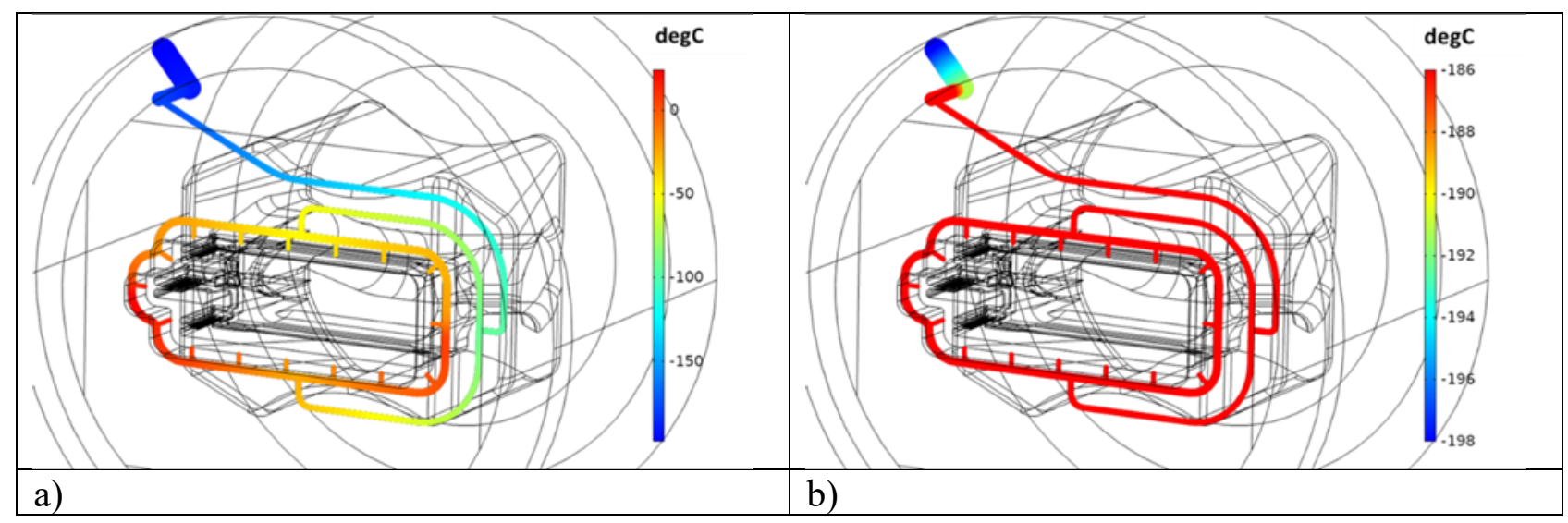

Fig.15 Thermal map of liquid nitrogen into the channel (billet 12): a) range of temperature along the channel, b) gas formation along the channel 
The proposed numerical model confirmed a good predictability of the results in terms of thermal field and extrusion load in the uncooled, gaseous cooled and liquid cooled extrusions. Moreover, the analysis clearly highlighted the limits of the tested cooling channel design, emphasising the importance of a proper tool to support the die design.

\section{Conclusions}

In the present work, an experimental campaign was presented with the aim to investigate the effect of the nitrogen cooling in the extrusion process of aluminium alloys and to validate a multiphysics FE model proposed by the authors that innovatively considered the effect of liquid and gaseous phases of the nitrogen. An industrial porthole die was identified, and the thermal field evolution was strictly monitored by several thermocouples placed nearby the cooling channel and the bearing zones.

The acquired temperatures showed a not optimized channel design that produced an unbalanced cooling in the backer and, to a less extent, in the die. The $40 \%$ of nitrogen flow rate was found to be inadequate to promote the liquid nitrogen flow within the channel. The $100 \%$ of nitrogen flow rate caused a detectable cooling in the backer only after the extrusion of 4 billets (billet 13) and a similar trend was found, with a minor extent, also in the die. In addition, the experimental results confirmed that a mixture of gas and liquid nitrogen was still present within the channel after a long transitory, and that the steady state cooled condition with liquid nitrogen was not reached experimentally within the 17 extrusions performed, thus limiting the cooling effectiveness.

Concerning the proposed FE model, the study evidenced that the discrete model approach (gaseous cooling only or liquid cooling only) provides clear indication on the average thermal distribution in the backer and in the die however highlighting also possible improvements. Specifically, nitrogen in the channel was experimentally proved to evolve with time from a $100 \%$ gaseous state at the beginning of the process to a $100 \%$ liquid state when steady-state condition is reached. The developed model was able to get only the two extreme conditions $(100 \%$ gaseous or $100 \%$ liquid) whilst most of the analysed conditions were in a phase mixture, thus clearly tracing the future developments of the present work.

Even stating the existing limits, the numerical-experimental matching was extremely accurate for the uncooled process as well as for the gaseous and liquid cooling. In more details, the developed model provided estimations with average errors below 5\% for the uncooled conditions, below 4,3\% in the die and below 7,5\% in the baker for the gaseous phase and below 5\% in the liquid phase in the die. In terms of profile temperatures and extrusion loads, errors remained below 1,3\% and $12 \%$, respectively, for uncooled simulations, below $0,6 \%$ and $13 \%$ for gaseous state and below $2,6 \%$ and $14 \%$ for liquid state simulations.

The achieved results suggest the reliability of the novel developed simulation tool and its potential integration in a flexible procedure to be used for process and die design optimization. Point of interest for future development is the implementation of new equations in the 1D numerical model in order to include the phase change of nitrogen during the extrusion process.

\section{Declarations}

Funding: not applicable

Conflicts of interest/Competing interests: authors do not have a financial relationship with the organization that sponsored the research. They should also have full control of all primary data and agree to allow the journal to review their data, if requested.

Availability of data and material: not applicable 
Code availability: commercial code COMSOL Multiphysics (software application)

\section{References}

[1] Saha PK (2000) Aluminum extrusion technology. ASM Int. Materials Par, Ohio

[2] Sheppard T (1999) Extrusion on Aluminum Alloys. Kluwer Academic Publisher, Boston

[3] Staley JT, Liu J, Hunt WH (1997) Aluminum Alloys for Aerostructures. Adv. Mater. Process. 152(4):17-20

[4] Saha PK (1998) Thermodynamics and tribology in aluminum extrusion. Wear. 218(2):179-190

[5] Parson NC (1996) Surface Defects on 6xxx Alloy Extrusions. Proceedings of the 6th International Extrusion Technology Seminar. 1:57-67

[6] Qamar SZ, Arif AFM, Sheikh AK (2004) Analysis of Product Defects in a Typical Aluminum Extrusion Facility. Materials and Manufacturing Processes. 19(3):391-405 https://doi.org/10.1081/AMP-120038650

[7] Qamar SZ, Pervez T, Chekotu JC (2018) Die Defects and Die Corrections in Metal Extrusion. Metals. 8(6):380 https://doi.org/10.3390/met8060380

[8] Akhtar SS, Arif AFM (2010) Fatigue failure of extrusion dies: Effect of process parameters and design features on die life. J. Fail. Anal. Prev. 10:38-49 https://doi.org/10.1007/s11668-0099304-4

[9] Stratton p (2008) Raising productivity of aluminium extrusion with nitrogen, International Heat $\begin{array}{llll}\text { Treatment and } & \text { Surface } & \text { Engineering. } & \end{array}$ https://doi.org/10.1179/174951508X429221

[10] Ward TJ, Kelly RM, Jones GL, Heffron J (1984) Effects of nitrogen - liquid and gaseous - on aluminum extrusion. The Journal of Minerals Metals \& Materials Society. 36(12):29-33

[11]Brodbeck H (1984) Experience Using Liquid Nitrogen for Die Cooling. Proceedings of the Third International Aluminum Extrusion Technology Seminar (ET 1984). Atlanta, Georgia, the Aluminum Extruders Council and the Aluminum Association. 1:279-282

[12] Marchese MA, Coston JJ (1988) Efficient Use of Liquid Nitrogen for Aluminum Extrusion Die Cooling and Inerting. Proceedings of Fourth International Aluminum Extrusion Technology Seminar (ET 1988). Chicago, Illinois, the Aluminum Extruders Council and the Aluminum Association. 2:83-88

[13] Mainetti E, Bertoletti M, Wallfish S, Ferrentino A (2012) Significant Extrusion Speed Increase using Liquid Nitrogen to Eliminate Overheating of Dies During Extrusion Process. Proceedings of the Tenth International Aluminum Extrusion Technology Seminar (ET 2012). Miami, Florida, Extrusion Technology for Aluminum Profiles Foundation. 1:201-206

[14]Donati L, Segatori A, Reggiani B, Tomesani L, Bevilacqua Fazzini PA (2012) Effect of liquid nitrogen die cooling on extrusion process conditions. Key Engineering Materials. 491:215-222 https://doi.org/10.4028/www.scientific.net/KEM.491.215

[15] Reggiani B, Todaro I (2019) Investigation on the design of a novel selective laser melted insert for extrusion dies with conformal cooling channels. International Journal of Advanced Manufacturing Technology. 104(1-4):815-830 https://doi.org/10.1007/s00170-019-03879-9 
[16]Ronald J, Selines F, Lauricella C (1984) Extrusion Cooling and Inerting Using Liquid Nitrogen. Proceedings of the Third International Aluminum Extrusion Technology Seminar (ET 1984). Atlanta, Georgia, the Aluminum Extruders Council and the Aluminum Association. 1:221-226

[17]Ciuffini AF et al (2018) Surface Quality Improvement of AA6060 Aluminum Extruded Components through Liquid Nitrogen Mold Cooling. Metals. 8(6):409 https://doi.org/10.3390/met8060409

[18]Lemmon EW, McLinden MO, Friend DG (2018) Thermophysical Properties of Fluid Systems. NIST Chemistry WebBook, NIST Standard Reference Database Number 69, Eds. P.J. Linstrom and W.G. Mallard, National Institute of Standards and Technology, Gaithersburg MD

[19] Norwood AJ et al (2004) Analysis of cooling channels performance. International Journal of $\begin{array}{lll}\text { Computer Integrated 17(8):669-678 } & \end{array}$ https://doi.org/10.1080/0951192042000237528

[20]Lurie MV (2008) Modeling of Oil Product and Gas Pipeline Transportation. WILEY-VCH Verlag GmbH \& Co., KGaA, Weinheim

[21] Gnielinski V (1976) New Equation for Heat and Mass Transfer in Turbulent Pipe and Channel Flow. Int Chem Eng. 16:359-368

[22] Bastani AF, Aukrust T, Brandal S (2011) Optimisation of flow balance and isothermal extrusion of aluminium using finite-element simulations. Journal of Materials Processing Technology. 211(4):650-667 https://doi.org/10.1016/j.jmatprotec.2010.11.021

[23]Zhang C, Zhao G, Chen H, Guan Y, Kou F (2012) Numerical simulation and metal flow analysis of hot extrusion process for a complex hollow aluminum profile. Int J Adv Manuf Technol., 2012, Vol. 60, pp. 101-110 https://doi.org/10.1007/s00170-011-3609-7

[24]Reggiani B, Donati L (2019) Prediction of liquid nitrogen die cooling effect on the extrusion process parameters by means of FE simulations and experimental validation. Journal of Manufacturing processes. 41:231-241 https://doi.org/10.1016/j.jmapro.2019.04.002

[25]Jiang Y, Wu R, Yuan C, Wang W, Jiao W (2019) Prediction and analysis of breakthrough extruding force based on a modified FE-model in large-scale extrusion process. Int J Adv Manuf Technol. 104:3531-3544 https://doi.org/10.1007/s00170-019-04039-9

[26]Liu Z, Li L, Yi J, Wang G (2019) Entrance shape design of spread extrusion die for large-scale aluminum panel. Int J Adv Manuf Technol. 101:1725-1740 https://doi.org/10.1007/s00170-0182991-9

[27]Reggiani B, Segatori A. Donati L, Tomesani L (2013) Prediction of charge welds in hollow profiles extrusion by FEM simulations and experimental validation. Int. J Adv. Manuf. Technol. 69(5-8):1855-1872 https://doi.org/10.1007/s00170-013-5143-2

[28]Lou S et al (2017) Analysis and Prediction of the Billet Butt and Transverse Weld in the Continuous Extrusion Process of a Hollow Aluminum Profile. Journal of Materials Engineering and Performance. 26(8):4121-4130 https://doi.org/10.1007/s11665-017-2771-y

[29] Reggiani B, Donati L, Tomesani L (2017) Multi-goal optimization of industrial extrusion dies by means of meta-models. International Journal of Advanced Manufacturing Technology 88(912):3281-3293 https://doi.org/10.1007/s00170-016-9009-2

[30] Lou S, Wang Y, Lu S, Su C (2018) Die structure optimization for hollow aluminum profile. Procedia Manufacturing. 15:249-256 https://doi.org/10.1016/j.promfg.2018.07.216 
[31] Kim YT, Ikeda K (2000) Flow Behavior of the Billet Surface Layer in Porthole Die Extrusion of Aluminum. Metallurgical and Materials Transactions A. 31A:1635-1643 https://doi.org/10.1007/s11661-000-0173-4

[32] Qamar SZ (2004) Modeling and Analysis of Extrusion Pressure and Die Life for Complex Aluminum Profiles. Ph.D. Thesis, King Fahd University of Petroleum \& Minerals, Dhahran, Saudi Arabia

[33] www.comsol.it

[34] Sellars CM, McG Tegart WJ (1972) Hot workability. Int Metall Rev. 17(1):1-24.

[35] Nourani M, Milani AS, Yannacopoulos S (2014) On the effect of different material constitutive equations in modeling friction stir welding: A review and comparative study on aluminum 6061. International Journal of Advances in Engineering \& Technology. 7(1): 1-20

[36] Verlinden B, Suhadi A, Delaey L (1993) A generalized constitutive equation for an AA6060 aluminum alloy. Scripta Metallurgica et Materialia. 28:1441-1446 https://doi.org/10.1016/0956716X(93)90496-F

[37] Schikorra M, Donati L, Tomesani L, Tekkaya AE (2007) The Extrusion Benchmark 2007. Proceedings of the Extrusion Workshop 2007 and 2nd Extrusion Benchmark Conference. Bologna 